\title{
Taking Aim on Empowerment Research: On the Distinction Between Individual and Psychological Conceptions ${ }^{1}$
}

\author{
Marc A. Zimmerman ${ }^{2}$ \\ University of Michigan
}

This paper examines two issues: (a) contributions of a special section of AJCP for understanding and studying citizen participation and empowerment, and (b) elaboration of the construct of psychological empowerment. Limitations of an individual level of analysis are discussed along with a more detailed description of psychological empowerment. A distinction between psychological empowerment and individually-oriented conceptions is made. The former includes person-environment fit and contextual issues, while the latter is primarily a trait conceptualization that may be antithetical to the idea of empowerment. Research strategies for future work on empowerment are suggested. This research requires us to build bridges across levels of analysis so we can fully understand the contextual and individual qualities that converge to form empowerment theory.

Empowerment theory is an enigma. Rappaport (1984) suggested that it is easy to define in its absence-alienation, powerless, helplessness - but difficult to define positively because it "takes on a different form in different people and contexts" (p. 2). It also differs across levels of analysis (Zimmerman, in press). At the individual level, empowerment includes participatory behavior, motivations to exert control, and feelings of efficacy and control. Organizational empowerment includes shared leadership, oppor-

${ }^{1}$ I thank Abraham Wandersman and Deborah Salem for their thoughful comments on earlier drafts of this manuscript.

${ }^{2}$ All correspondence should be sent to Marc Zimmerman, Department of Health Behavior and Health Education, School of Public Health, University of Michigan, 1420 Washington Heights, Ann Arbor, Michigan 48105. 
tunities to develop skills, expansion, and effective community influence. Empowered communities comprise empowered organizations, include opportunities for citizen participation in community decision making, and allow for fair consideration of multiple perspectives during times of conflict. Empowerment at all levels of analysis can have different intensities that can change over time. It is not an absolute threshold that once reached can be labeled as empowered. Empowerment embodies an interaction between individuals and environments that is culturally and contextually defined. As a result, interdisciplinary approaches, paradigm shifts, and creative research strategies may be required to fully understand the construct.

This special section of the American Journal of Community Psychology adds to the development of empowerment theory by identifying settings and conditions in which residents may exert control in their communities. This research also provides examples of how empowerment and participation can be studied at multiple levels of analysis. Finally, the empirical papers borrow from disciplines outside of psychology to help define research strategies and interpret the results. Empirically based analyses such a those presented in this special section provide a foundation upon which to build empowerment theory and advance the debate about what it is and what it means. The inclusion of comments by communty participants, in this special section, is consistent with the idea of empowerment and provides useful anecdotal information. Each paper adds a distinctive understanding about the empowerment process, while also building on past research.

The special section also raises an interesting issue about the role of the individual level of analysis in empowerment theory. After I comment on the contributions of the individual papers to empowerment theory, I further delineate the construct of psychological empowerment and distinguish it from individually oriented conceptions of empowerment. The difference between these two interpretations is both significant and necessary. It is significant because paradigmatic limitations may prohibit the full development of empowerment theory. It is necessary to distinguish these two interpretations in order to avoid ignoring a major ingredient of empowerment theory - the individual.

\section{CONTRIBUTIONS OF THE SPECIAL SECTION}

The paper by Prestby, Wandersman, Florin, Rich, and Chavis (1990) employs a person-environment fit approach that integrates individual and 
organizational levels of analysis. Analysis of the effects of perceived benefits and costs of participation provides a unique understanding of psychological empowerment. They found that the most highly involved individuals reported more benefits of participation - learning new skills, gaining information, helping others, increasing social contact, and fulfilling obligations - than less-involved individuals. This is consistent with previous research on psychological empowerment (Kieffer, 1984; Zimmerman \& Rappaport, 1988). Prestby el al.'s research expands on these previous results, however, by identifying some of the facilitating and inhibiting factors that may influence individuals' choice regarding their level of involvement.

Prestby et al.'s (1990) efforts to understand the link between management strategies and organizational viability provides a good example of research on organizational empowerment as well. Their examination of the connection between incentive management and organizational activity suggests that organizational empowerment may be linked to person-environment fit. Individuals motivated by factors such as social ties, skill building, and helping others may help to empower organizations that have shared decision making, open leadership, and communal projects, but may not strengthen hierarchically defined organizations that provide few opportunities to become involved in organizational tasks. Similarly, organizations may not be empowering for participants who expect to become involved in decision making and problem solving but find they must first work their way through a leadership hierarchy that provides few opportunities for meaningful involvement. Future research could examine how the connection between organizational structure and members' motivations may influence both the empowering potential of a setting and the extent to which the organization can attract participants, expand, and achieve its goals.

The model presented by Chavis and Wandersman (1990) helps to further specify variables that may mediate the relationship between participation and empowerment. They suggest that sense of community plays an important role in the development of personal control and participation. They found that sense of community had a direct effect on one's level of involvement in a neighborhood association and it has an even stronger effect on constructs that are directly linked to empowerment - environmental perception and perceived control. This is consistent with Maton and Rappaport's (1984) finding that sense of community was associated with individual empowerment for members of a religious organization.

Perhaps the most important contribution of Chavis and Wandersman's (1990) paper comes from the results of their longitudinal analysis. They suggest a reciprocal relationship between a sense of community and participation and a sense of personal power and participation. 
This is consistent with empowerment theory which postulates that participation in decision making may enhance one's sense of empowerment and that empowered individuals are likely to be active in community organizations and activities (Kieffer, 1984; Zimmerman, in press; Zimmerman \& Rappaport, 1988). The fact that participation and perceptions of group power were not correlated suggests that other factors (e.g., organizational effectiveness, sense of community) may mediate the relationship between these two variables. The work by Prestby et al. (1990) suggests that skills learned and information gained may also help determine whether or not participation contributes to the development of empowerment for individuals or organizations. The longitudinal results also lend support for a model of learned hopefulness (Zimmerman, 1990). This model, posited as a counterpart to learned helplessness theory, suggests that efforts to exert control may increase one's sense of empowerment.

Chavis and Wandersman (1990) also found that individuals may develop a sense of control even if they do not perceive group power to change over time. This suggests that empowering organizations (i.e., those that contribute to the development of psychological empowerment) are not necessarily empowered organizations (i.e., those that influence the policy process and remain viable over time). This finding illustrates the need to recognize that interentions aimed at strengthening community organizations may not improve their empowering potential, or conversely, that interventions aimed at improving the empowering potential of organizations may not help the organizations to become empowered. If our goal is to both empower the organization and enhance its empowering potential, then we may need to develop interventions specifically designed to address both issues. This means that our interventions would have to focus on decisionmaking structures and social climate, as well as organizational expansion and coalition building (i.e., networking among other organizations).

The paper by Perkins, Florin, Rich, Wandersman, and Chavis (1990) provides another perspective for studying a context in which to understand empowerment. Their focus on the physical environment is an innovative approach to understanding the development of psychological empowerment. They go further, however, by examining how the social milieu and the physical environment interact to mobilize an individual into aciton. Their results build on the Chavis and Wandersman (1990) study by identifying one of the conditions - unacceptable physical conditions of a neighborhood - when social climate (e.g., sense of community, neighboring) might act as a catalyst for action. Future research could build on this approach by examining factors thay may inhibit the catalytic potential of empowering social climates. 


\section{LIMITATIONS OF AN INDIVIDUAL LEVEL OF ANALYSIS}

All three studies point out the importance of expanding our understanding of empowerment beyond the individual level of analysis. The authors suggest that an overly individualistic conception of empowerment may limit our understanding of the construct. If we focus exclusively on the individual level of analysis we may unwittingly advance single measures of competence and trait-oriented conceptions of empowerment while failing to consider environmental influences; organizational factors; or social, cultural, and political contexts. An individual focus may also limit our choices for research methods and designs to those most familiar and acceptable to psychologists. This may make it easy to overlook the theories and alternative research strategies offered by other disciplines (e.g., anthropology, education).

An interdisciplinary approach to empowerment research may be necessary for addressing the difficulty we have in defining the construct. Van Uchelen (1989) provided an example of how an interdisciplinary perspective can enhance our way of thinking about empowerment. He introduced a view of control theory that has a collective rather than an individual orientation. He distinguished between traditional perspectives of control that focus on individual action and perception (e.g., learned helplessness, self-efficacy) and an alternative approach that emphasizes "control-as-meaningfulness in a collective context" (p. 5). A more contextual and collectivist orientation does not ignore individual experiences of control, rather, it allows for a more culturally sensitive theory of control that is consistent with empowerment theory. The authors in this special section integrate theories from other disciplines to provide a suitable framework for investigating empowerment, while also incorporating contextual influences in their research.

\section{PSYCHOLOGICAL EMPOWERMENT VERSUS INDIVIDUALLY ORIENTED APPROACHES}

We must not go too far, however, in rejecting the individual level of analysis. Rather, we need to distinguish between individually oriented conceptions of empowerment and psychological empowerment. The former neglects contextual considerations, is limited to a single paradigm, and treats empowerment as a personality variable. The latter (i.e., psychological empowerment) refers to the individual level of analysis, but does not ignore ecological and cultural influences. Psychological empowerment is a contex- 
tually oriented conception of empowerment that embraces the notion of person-environment fit. It includes, but is not limited to, collective action, skill development, and cultural awareness; and incorporates intrapsychic variables such as motivation to control, locus of control, and self-efficacy. The challenge for researchers interested in empowerment is not to ignore one level of analysis in the interest of another but to struggle with efforts to integrate levels of analysis for understanding the construct in its entirety. The three studies described in this special section point us in this direction.

While all three empirical papers examined contextual variables and their relationship to participation and empowerment, they did not ignore the psychological nature of the construct. Including individual level variables in empowerment research is not necessarily contrary to the interests of collective action and social change, or for that matter Community Psychology. Contextual factors are an essential component of empowerment theory but equally critical are intrapsychic factors such as cognitive, personality, and motivational aspects of control. The goal is to understand how what goes on inside one's head interacts with what goes on in one's environment to enhance or inhibit one's mastery and control over the factors that affect one's life. Depending on the person and context this may be maintaining a life outside of an institution, coping with a divorce, or successfully influencing a city council decision.

\section{Psychological Empowerment}

Psychological empowerment requires a contextual analysis to be fully understood. For example, an empowered person may have no real power in the political sense, but may have an understanding of what choices can be made in different situations. Glidewell (1970) described the difficulties one faces when working and living with people, and the choices one must make: whether to fight or give in, whether to be dependent or dependable, and whether to seek help or provide assistance. Empowered individuals may not always make the best (or correct) choices, but they may know that they can choose whether to fight or retreat, to be dependent or independent, and to organize or wait.

Psychological empowerment also includes an understanding of the factors that influence decision making processes. Sue and Zane (1980) presented the notion of causal agents-factors that influence decisionmaking processes that effect individual, organizational, and community well-being. Causal agents may be people such as elected officials, resources such as money, or events such as natural disasters. Empowered persons are aware of the factors that influence the causal agents within the life domains 
they decide are imporant. For example, citizens interested in eliminating toxic dumping in their community may attempt to influence both elected officials and industry executives to stop toxic dumping, however, their strategies to influence these causal agents may be different. A petition drive of registered voters may be most effective for persuading an elected official, but the executive may be more influenced by a protest march in his or her own neighborhood than the threat of losing electoral support. Similarly, the choice to boycott a product may have a greater impact on the actions of an industry executive than writing letters to a congressperson about the industry's behavior. Ultimately, psychological empowerment is a contextual construct that requires an ecological analysis of individual knowledge, decision-making processes, and person-environment fit.

\section{Strategies for Researching Empowerment}

The research methods we use for studying empowerment will inevitably be a limiting or facilitating factor in our understanding of the construct. As long as we continue to use primarily quantitative methods we will have a limited understanding of the construct. Qualitative approaches such as in-depth case histories, investigative reporting (Levine, 1980), and participant observation are useful starting points for expanding our repertoire of research methods. For example, Kieffer (1984) used an innovative approach for describing the empowering experiences of several grass-roots leaders. He interviewed the leaders, summarized the interviews, and asked the leaders to comment on the summaries. This process not only helped to validate the data, but it provided the leaders with another opportunity to reflect on their experiences.

The inclusion of the papers by Kaye (1990) and Burgess (1990) in the special section contribute a qualitative perspective to the quantitative analyses presented. The authors provide information about the research process and their own experiences that is necessarily missing in quantitative approaches. Their comments reinforce the quantitative data presented and, as a consequence, further strengthen the research. Kaye (1990) provides a critical analysis of the research process and gives future researchers advice that may help improve entry, cooperation, and collaboration. She also tells us how we can be helpful to grass-roots organizations. These insights support Prestby et al.'s (1990) finding that potential skill development is an important motivator for participants. Kaye's (1990) discussion of this process from a participant's perspective embellishes our understanding of the quantitative results. Burgess (1990) tells us how important social contact and fellowship are for maintaining involvement in a neighborhood association. He is essentially telling us, from the perspective of a community leader, that 
the results of the Chavis and Wandersman (1990) and Perkins et al. (1990) papers are on target. The comments by these two community leaders not only validate the quantitative results but provide us with useful lessons for future research with grass-roots organizations and leaders. Incorporating comments by research participants in the reporting of our results adds to our understanding of empowerment and strengthens our conclusions. It also exemplifies our value to be inclusive rather than exclusive, engaging rather than controlling, and empowering rather than patronizing.

\section{SUMMARY}

Empowerment theory need not remain a mystery. Efforts, such as those described in this special section, to outline more clearly the nomological network of empowerment at multiple levels of analysis will advance empowerment theory. Tough-minded rigorous research is needed to advance the concept of empowerment. Empowerment research requires us to shift our attention from a debate between the merits of research at one level of analysis versus another to building bridges between levels of analysis. We must integrate theories and methods from other disciplines and develop research strategies that incorporate qualitative procedures and the voices of the research participants. The papers in this special section take aim on these tasks and add to our understanding of empowerment.

\section{REFERENCES}

Burgess, L. (1990). A block association president's perspective on citizen participation. American Journal of Community Psychology, 18, 159-162.

Chavis, D. M., \& Wandersman, A. (1990). Sense of community in the urban environment: A catalyst for participation and community development. American Journal of Community Psychology, 18, 55-82.

Glidewell, J. C. (1970). Choice points. Cambridge, MA: MIT Press.

Kaye, G. (1990). A community organizer's perspective. American Journal of Cornmunity Psychology, 18, 151-158.

Kieffer, C. (1984). Citizen empowerment: A developmental perspective. Prevention in Human Services, 3, 9-36.

Levine, M. (1980). Investigative reporting as a research method: An analysis of Bernstein's \& Woodward's "All the President's Men." American Psychologist, 35, 626-638.

Maton, K. I., \& Rappaport, J. (1984). Empowerment in a religious setting: A multivariate investigation. Prevention in Human Services, 3, 37-72.

Perkins, D. D., Florin, P., Rich, R. C., Wandersman, A., \& Chavis, D. M. (1990). Participation and the social and physical environment of residential blocks: Crime and community context. American Journal of Community Psychology, 18, 83-116.

Prestby, J. E., Wandersman, A., Florin, P., Rich, R. C., \& Chavis, D. (1990). Benefits, costs, incentive management and participation in voluntary organizations: A means to understanding and promoting empowerment. American Journal of Community Psychology, 18, 117-150. 
Rappaport, J. (1984). Studies in empowerment: Introduction to the issue. Prevention in Human Services, 3, 1-7.

Sue, S., \& Zane, N. (1980). Learned helplessness theory and Community Psychology. In M. S. Gibbs, J. R. Lachenmeyer, \& J. Sigal (Eds.), Community psychology: Theoretical and empirical approaches (pp. 121-143). New York: Gardner.

Van Uchelen, C. (1989, June). Healing mechanisms of self-help: Toward a non-individualistic conception of control. Paper presented at the Second Biennial Conference on Community Research and Action, East Lansing, MI.

Zimmerman, M. A. (1990). Empowerment: Forging new perspectives in mental health. In J. Rappaport, \& E. Seidman, (Eds.), Handbook of community psychology, New York: Plenum Press.

Zimmerman, M. A. (1990). Toward a theory of learned hopefulness: A structural model analysis of participation and empowerment. Journal of Research in Personality, 24, 71-86.

Zimmerman, M. A., \& Rappaport, J. (1988). Citizen particpation, perceived control, and psychological empowerment. American Journal of Community Psychology, 16, 725-750. 